\title{
The involvement of the key participants in the production of project plans and the planning performance of refurbishment projects
}

Received (in revised form): 7th October 2009

\section{Ismail Rahmat}

is an associate professor in the Department of Building, Faculty of Architecture, Planning and Surveying, Universiti Teknologi MARA, Malaysia. He obtained his PhD in Construction Management from Universiti College London, UK. He is a corporate member of the Chartered Institute of Building, UK. He has published a number of papers and a book on refurbishment works.

\begin{abstract}
Azlan Shah Ali
is a senior lecturer in the department of Building Surveying, Faculty of Built Environment, University of Malaya, Malaysia. He has a PhD in Built Environment, specialising in building refurbishment, and a Bachelors degree (honours) in Building Surveying from Universiti Teknologi MARA, Malaysia. He is also a corporate member of the Institution of Surveyors, Malaysia and The Chartered Institute of Building, UK (MCIOB). Dr Azlan has been involved in a number of academic research and publications. He has published several papers, both in local and international journals.
\end{abstract}

Correspondence: Ismail Rahmat, Building Department, Faculty of Architecture, Planning and Surveying, Universiti Teknologi MARA, Shah Alam 40450, Malaysia

ABSTRACT Building refurbishment, which includes repair, conversion, renovation, restoration, conservation, retrofit and new-build extension, is an important sector in the construction industry of most developed countries. Planning for refurbishment projects is demanding because of their inherent complexity and uncertainty. It has been argued that in order to manage the uncertainty and improve performance, planning for refurbishment projects needs a more flexible and participative approach. This article measures the degree of involvement of the key participants in the production of project plans of refurbishment projects. It also establishes the relationship between the involvement of the key participants in the production of project plans and planning performance. The data were obtained from literature review, semi-structured interviews and a postal questionnaire survey that involves 67 Planning Engineers and Contract Managers. This article concludes that specialisation of tasks predominates in the planning process of refurbishment projects and the involvement of the clients in the production of master programme helps to improve planning performance.

Journal of Building Appraisal (2010) 5, 273-288. doi:10.1057/jba.2009.34

Keywords: refurbishment; involvement; project plans; planning performance

\section{INTRODUCTION}

Refurbishment is defined as making use of what is usable in the ageing building stock, the skilful adaptation of building shells (which is valuable in its own right and not owing 
to any historic mystique) to a new or an updated version of its existing use (Marsh, 1983, p. 3). It excludes scheduled repair and maintenance, though it may include opportunistic work of this nature.

Refurbishment is an important sector of the construction industry of most developed countries. However, there are no official statistics on the actual value of refurbishment work. In the United Kingdom, for instance, refurbishment works are categorised under repair and maintenance. Young et al (1996) observed that the Department of Environment's statistics on repair and maintenance sector are generally accepted by practitioners, government establishments and academics as the basis for monitoring trends in the refurbishment sector. From 2000 to 2008, the proportion of the repair and maintenance output constituted around 40 per cent of the total output of building sector (ONS, 2009). If illegal and unreported refurbishment works carried out by house owners are included, the actual value of refurbishment work in the United Kingdom would be higher.

Managing refurbishment projects is demanding because of their inherent complexity and uncertainty. However, the organisation, contractual arrangement, education and training in the construction industry are more centred to new construction. Compared with new build, refurbishment needs a more flexible and integrated approach (Boyd and Weaver, 1994). However, many refurbishment managers use the same approach as for new build with only slight modifications.

Within the area of refurbishment management, planning is the most difficult function facing refurbishment managers (Egbu, 1994). It has to be done under uncertainty, that is, with insufficient and incomplete information, under constantly changing conditions.

Okoroh (1992) pointed out that the inadequacy of specifications from the architects makes it difficult for contractors to define the exact scope of work in advance. Therefore, it is difficult to produce Method Statements and Master Programmes and to determine the actual time and cost of the works (CIOB, 1988). Unlike new build, much of planning for refurbishment is being carried out during project execution. Planning for refurbishment projects is also very time-consuming, especially when the process involves systematic gathering of external data, such as the availability of material, plant and equipment and the productivity of labour.

Quah (1992) found that regardless of project size, refurbishment tenders had a higher bid variance than new build. This is because of the inadequacy of specifications arising from inadequate surveys and unfamiliarity with the technical problems of refurbishment work. In addition, the majority of refurbishment projects are delayed. This reflects the uncertainty of refurbishment projects. Therefore, greater emphasis should be placed on managing the complexity and uncertainty of refurbishment projects.

Lawrence and Lorsch (1967) said that that the greater the uncertainty facing an organisation, the greater was the need for specialisation to cope with the additional information. Increased specialisation within an organisation tends to increase differentiation, that is, the various sub-units having different attitudes, patterns of interpersonal communication, formal hierarchies and time horizons. Some units reacted more to short-term problems than to long-term opportunities. The greater the degree of differentiation in the organisation, the more pressure to achieve integration.

In order to cope with uncertainty, many participants with specialised skills are employed in the planning process of refurbishment projects. The major task in the planning process is the production of various types of project plans. Four types of project plans are the most commonly used, that is, Master Programme, Method Statement, ShortTerm Plans and Site Layout. The need to produce many plans encourages specialisation that, in turn, causes differentiation in the planning process. Hence, there is a strong 
pressure for integration, which, among others, can be achieved through the involvement of the key participants in the planning process.

Therefore the objectives of this article are:

1. To establish the degree of integration in the planning process of refurbishment projects by measuring the relative degree of involvement of the key participants in the production of project plans.

2. To establish the relationships between the degree of involvement of the key participants in the production of project plans and the planning performance of refurbishment projects.

\section{INTEGRATION IN THE PLANNING PROCESS}

Uncertainty has been examined from an information processing point of view. Galbraith (1977) said that the greater the uncertainty of tasks that need to be performed by the participants, the greater the amount of information that has to be processed during the execution of the task. Task uncertainty depends on the number of participants involved in the process and the degree of inter-relatedness of their tasks. The higher the number of participants involved, the greater the volume of information that needs to be processed. Similarly, the higher the degree of inter-relatedness of the tasks of the participants, the higher the amount of information that needs to be processed.

Thus complexity and uncertainty create twin problems, the need to differentiate the tasks to be performed in organisations and the need to integrate the interrelated tasks.

The specialisation of tasks between the multiple participants in a project organisation tends to create communication gaps, which could delay the process of decision making and implementation. Koontz and O'Donnel (1972) described this as the 'planning gap'. Laufer and Cohenca (1988) observed the specialisation of tasks in the planning process of construction projects and concluded that the specialisation of tasks, for example, between formal authority and technical expertise is untenable and artificial. Laufer and Cohenca (1988) emphasised that securing planning integration is a crucial task.

The main emphasis in project planning literature, training and education is on the techniques of project planning, and in particular those concerned with scheduling of work and cost estimating (Harrison, 1992; Laufer et al, 1994). This tendency is largely attributed to the influence of the owner, the goals of construction projects and the training of construction planners. However, there is much more to project planning and control than the use of those techniques. Laufer et al (1992), for instance, maintain that more emphasis should be placed on the area of the planning process, that is, on the integration of interrelated decisions made by various participants. The studies conducted by Cohenca-Zall et al (1994), Cohenca et al (1987), Faniran et al (1994), Laufer et al (1993), Laufer et al (1994), Syal et al (1992) are the most notable ones in this area.

The review of literature also reveals that research on planning of refurbishment projects is still sparse. In the area of scheduling, only studies conducted by Whiteman and Irwig (1988) and Fiedler (1987) are of considerable interest. In the area of the planning and control process, the study conducted by Young et al (1996) is the only notable one.

It is more difficult to plan refurbishment projects, which generally have a higher degree of uncertainty than new build. Uncertainty makes it less effective to determine actions and outcomes. According to Laufer et al (1994), sophisticated models for planning are inadequate for coping with uncertainty in construction projects. Therefore, many refurbishment managers find it difficult to make making strategic choices on goals, organising modes and for integrating individuals in the organisation. 
According to Walker (1989), the complexity of constructional works and clients' demands and technological developments have over the years resulted in specialisation within the construction industry. The large number of specialists who contributed to the decision-making process reflects the existence of differentiation in construction process.

The review of literature suggested that the following factors are the cause of the differentiation:

1. The high degree of specialisation of tasks

2. The contractual system

3. The shortage of time of project managers and Site Managers to plan

4. The lack of knowledge, training and experience of site management in Master Programme

McGowan et al (1993) pointed out in small building projects, with a lesser degree of task specialisation, planning and control tasks among the key participants overlap. This situation is linked to unclear definition of responsibility and greater tendency for conflicts to occur within the construction project organisations. The specialisation of tasks is to avoid this conflict.

Hillebrandt (1974) and O'Brien (1984) maintain that fixed-price construction projects gave rise to contracting uncertainty. The traditional procurement system hindered early planning during the engineering design and pre-bid stage because of economic considerations and low rate of bid success. Hence, the pre-bid planning is left to the Planning Engineers.

As contractors have little control over the pace and timings at which bids are issued, and less still over awards of contracts, it is very difficult to pull out a project manager from an active project and to assign the project manager immediately to a new one. Even when this is possible, the short interval, until the required mobilisation date stipulated by the owner, leaves the project manager with no time for preparatory planning. The project manager must turn his attention immediately to putting a new organisation together (Stukhart et al, 1986).

Syal et al (1992) observed that in many construction projects, a working project manager or Site Manager simply does not have the time to formally re-plan the project whenever changes in construction occur. As a result, in most small size firms and even in some moderate size construction firms, the construction project planning decisions are often made in ad hoc fashion and as the problems arise. Laufer and Tucker (1988) pointed out that the planning task is performed by a combined effort of a cost Estimator, whose primary concern is the 'final number' and Planning Engineer or an outside consultant, whose primary responsibility is to 'put together' a construction schedule. The shortage of time of construction managers is not limited to projects in progress, but also applies equally to the interval before commencement of projects.

In order to overcome the problem of shortage of time and lack of technical expertise of Site Managers, the majority of large construction firms employ Planning Engineers, or set up a separate planning department that effectively take the responsibility for any re-planning from the hands of site management. Consequently, differentiation among Planning Engineer and the contract management and site management are created with the Planning Engineers tending to concentrate on long-term planning and the Site Managers tend to concentrate on short-term project planning. Furthermore, some construction and Site Managers are also reluctant to be involved in long-term project planning, as they dislike having to commit and display their plans or lack of them to 
senior management (Harrison, 1992). Hence, long-term planning is left to the Planning Engineers.

Harrison (1992) maintained that even if Site Managers have plenty of time and the motivation to do so, their involvement could still be hampered if their knowledge in the production of plans is lacking. Laufer et al (1994) highlighted that much time for planning is required for documentation and the preparations of plans (in the forms of tables, charts and diagrams), as well their dissemination and communication. The presentation of decisions into plans requires special training, technical skill and experience in the use of computer and planning software. The Site Managers who have little experience and knowledge of the techniques of such project planning may find it difficult to think systematically and anticipate events especially in complex and uncertain projects like refurbishment.

The production of projects plans involves decision making. Galbraith (1977), Marsh and Simon (1958), and Cyert and March (1963) suggested that much of what goes on in organisation is decision making and information processing. The large number of people involved in the decision-making process is reflected by their limited ability to process information.

Decision making is universally accepted as the central role of management (Buffa, 1976). Simon (1960) went further by saying that decision making was synonymous with management. Dermer (1977) also pointed out that the essence of planning is collecting information and making decisions. Laufer et al (1994) noted that planning is a mentally demanding and complicated process. Construction planning is particularly difficult. It has to be done under constantly changing conditions, much of it being carried out during project execution, with insufficient and incomplete information. Construction planning is also time-consuming, especially when the process involves systematic gathering of external data, such as availability, cost and productivity of construction resources.

Walker (1989) suggested that the best way to manage the complexity and uncertainty of construction projects is by greater integration of decision making among the key participants. Integration is a concept put forward by Lawrence and Lorsch (1967: p. 4), who defined it as 'the extent to which the activities of individuals are closely co-ordinated in relation to the project objectives'. It is facilitated by effective formal channels of communications and through reliable and accessible information for staff about their jobs and their firms (Marsh and Simon, 1958; Burns and Stalker, 1961; Lawrence and Lorsch, 1967; Galbraith, 1977). Effective channels of communications and reliable and accessible information could be achieved by involving the key participants in decision making (Walker, 1989).

\section{THE TYPES OF PROJECT PLANS USED IN REFURBISHMENT PROJECTS}

In the project planning process, the most important activities are the production of four major plans, that is the Master Programme, Short-Term Plans, Method Statement and Site Layout.

\section{The Master Programme}

The contractors normally prepare a Master Programme that shows the relationship between an activity and the preceding and succeeding activities for the whole project. From the Master Programme, the resources required can be calculated. Without a programme of work, the execution of the contract will be haphazard and disordered.

The Bar Chart is the most common technique used for producing Master Programme in refurbishment projects (Rahmat, 1997). The Bar Chart is normally chosen because of the 
acceptance by all levels of management within the firm. However, in big construction firms, other planning techniques such as Critical Path Method, Precedence Diagram and Line of Balance are also used. This could be attributed to the higher knowledge on planning of the managers in such firms.

The popularity of Bar Chart in refurbishment projects is mostly attributed to its flexibility. Refurbishment projects tend to have a higher degree of variation, and a higher element of uncertainty. Therefore, most of the contractors require a planning technique that could be produced and revised speedily. Besides, Bar chart is simpler and easier to understand. This would enable more key participants to be involved in the production of the Master Programme.

The constraints imposed by the buildings to be refurbished, such as space and occupancy, make it difficult to conduct full investigation before commencement of work on site. This could lead to poor design documentation that in turn leads to greater changes made to the design during construction. The lack of information and changes made to the design reduce the accuracy of the Master Programme and could make it an ineffective tool for monitoring and controlling. However, the use of Information and Communications Technology could help to increase information processing capacity, which enable revisions of Master Programme and other project plans to be made quickly.

\section{The Short-Term Plans}

The Short-Term Plans, that is project plans that show the weekly or fortnightly work schedules are normally led and produced by the Site Managers. The Short-Term Plans enable the schedule in the Master Programme to be analysed into further detail. This directly involves Site Managers in decision making. The production of weekly project plans is normally carried out simultaneously with the revision of Master Programmes. This is done in order to keep the Master Programme under constant review and responsive to the changing and unforeseen circumstances. New requirements that necessitate changes to be made to the Master Programme are highlighted in the production of Short-Term Plans. The integration of the two processes, that is the revision of Master Programme and the preparation of Short-Term Plans helps the site management to be aware of the factors affecting the use of labour, materials and plant and the effects on completion date for each stage of work. It also enables Subcontractors and suppliers to be closely integrated into the planning process.

\section{The Method Statement}

The Method Statement is widely used in construction projects. Cooke (1993) informs us that where organisations use a centralised head office, the regional office may be responsible for the preparation of the Method Statement for enquiries within its own region. The regional Contracts Manager will prepare the Method Statement and assessment for contract preliminaries and submit these to the chief Estimator for discussion at the main tender meeting. The planning department and/or Planning Engineers are always consulted on the production of Method Statements.

When methods of construction have been agreed, the Estimator needs to interpret the methods into realistic bill rates. The methods used by the Estimator to prepare bids during the pre-bid stage could be changed, but normally fall within the budgeted costs. In most construction companies, after the pre-bid stage, the involvement of the Estimator in the production of all project plans reduces sharply.

The Method Statement is also used by the construction project managers to explore alternatives during the pre-construction stage. Therefore, the construction methods 
allowed for in the estimate must be flexible enough to enable reconsideration at the pre-contract planning stage as more detailed information becomes available. It is also used as a guide for the site management for planning and control, for example, as the basis for requisitioning plant and forecasting the labour force needed. Hence, the involvement of Estimator in the production of Method Statement is vital.

\section{The Site Layout}

The Site Layout plans are mainly concerned with the efficiency of movement on the construction project site. Among the major decisions taken in the production of Site Layout is the provision of adequate access roads, location of major plant and areas for storage of materials. Cormican (1985) observed that the Planning Engineer and/or Contracts Manager would prepare the Site Layouts and discuss them with Clients.

\section{THE INVOLVEMENT OF THE KEY PARTICIPANTS IN THE PRODUCTION OF PROJECT PLANS AND PLANNING PERFORMANCE}

Cormican (1985) said that the ultimate test of the success of a decision is whether the decision-maker can impel others to implement it. The extent and manner in which the implementers are involved in the decision-making process materially affects the success of implementation. This has been substantiated in the case of low-level workers performing routine tasks (for example, Jenkins and Lawler, 1981), and applies even more significantly to managers in charge of complex operations. Bass and Leavitt (1963) showed that performance and attitudes were better when subjects were using plans developed by themselves rather than by others.

Bresnen (1990) maintained that if organisations do not consciously choose to co-ordinate the involvement of the key participants in decision making, reduced performance standards will happen automatically. Similarly, Laufer et al (1996) argued the need for multi-phased integration, that is the leader of the next phases of the project need to be involved in planning from the earliest possible moment and in all subsequent phases. Multi-phased integration is facilitated when the contract is a long-term commitment of the partners. Multi-phased integration helps to improve communication flow and feedback systems. The involvement of implementers in upstream decisions would certainly improve the quality of downstream decisions. The product would be greater teamwork and job satisfaction.

Human relations theory made the simple assumptions that there is a causal chain from involvement in decision making to increased satisfaction. Heller et al (1989) and Miles (1965) found that skill under utilisation is a function of low involvement in the decision process. To make better use of existing experience and competence, decision-making practices have to allow key participants to exert influence. By allowing the participants to exert their influence will lead to increased satisfaction, in turn leads to a greater acceptance of authority and consequently improved performance. Performance in decision making is measured in terms of the extent to which desired outcomes have been achieved.

Maslow's self-actualisation theory of human behaviour can be used to argue that participative behaviours favours self-actualisation and this in turn allows untapped reservoirs of human production resources to be used. Similarly, Likert (1967) observed that the creative abilities of employees and their involvement were important as important motivating factor as financial rewards.

However, the influence of involvement on the work performance is not conclusive. Likert (1967), Tannebaum (1968), Kavic et al (1971), Argyris (1972), Pennings (1976), 
Dickson (1981) and Miles (1965) found positive associations between involvement and work performance, but the results were not supported in Filley et al's (1976) study. For construction projects, Faniran et al (1994) discovered that increased planning time reduced cost variance and time variance.

The above literature points to the importance of integration and involvement in decision making. However, it cannot provide conclusive evidence that involvement in decision could produce a better planning performance. Thus, it would be interesting to investigate to what extent the involvement of the key participants influence the project performance. Furthermore, research on involvement of managers in decision making for construction projects is still sparse. Studies by Laufer et al (1993) and Faniran et al (1994) are the most notable ones, but they focussed mainly on the level of involvement of managers for new construction projects.

\section{RESEARCH METHODOLOGY}

This study adopted the opinion research methodology, which is a combination of survey research, semi-structured interviews and postal questionnaire survey. The main objective of the semi- structured interviews was to refine the research problems and to set the theoretical framework for the study. The selected interviews with the firms' representative provided a framework and in-depth discussions for assessing the scope of questions needed for the postal questionnaire survey.

Since the emphasis of this study was on medium and large refurbishment projects, only Planning Engineers and Contract Managers from refurbishment firms undertaking refurbishment projects with a contract value of more than $£ 500000$ were involved. The study was done in two stages. Stage One, is semi-structured interviews and Stage Two, is postal questionnaire survey.

Fifteen construction firms with annual turnovers ranging from $£ 3$ to $£ 200$ million per annum were chosen to be interviewed. The interviews took place at the head offices of the refurbishment construction firms. One hundred and sixty-six planning and control managers from 94 construction companies were selected for the postal questionnaire survey. Sixty-seven (40 per cent) of returned questionnaires were considered to be useful for statistical analysis. The size of refurbishment projects analysed in this study is shown in Table 1. Spearman's correlation coefficient test was used to measure the relationships between two variables. The null hypotheses were rejected at the 5 per cent significant level.

\section{DATA ANALYSIS AND DISCUSSION}

The degree of integration of the key participants in planning is determined by measuring the level of involvement of the key participations in the production of four project plans. The key participants and the four project plans were identified from the semi-structured interviews. The key participants are the Planning Engineer, Contract Manager, Site Manager, Estimator, Subcontractors and Clients. The four types of project plans are the Master Programme, Short-Term Plans, Method Statement and Site Layout.

Table I: The size of refurbishment projects surveyed

\begin{tabular}{lc}
\hline Size of project (in million pounds) & Refurbishment projects (N=67), \% \\
\hline $0.5-1.0$ & 22 \\
$1.1-1.5$ & 24 \\
$£ 1.6-2.0$ & 15 \\
$£ 2.1-2.5$ & 6 \\
$£ 2.6-3.0$ & 3 \\
More than $£ 3.0$ & 30 \\
\hline
\end{tabular}


The involvements of the key participants in decision making for the production of the project plans will help to facilitate effective channels of communication through having accessible and reliable information. The degree of integration in the planning is directly proportional to the degree of involvement of the key participants in decision making. The degree of involvements of the key participants were recorded on a 4-point scale ranging from 1 (not involved), 2 (low involvement), 3(moderate involvement) to 4 (high involvement). The results are shown in Table 2 and Figure 1.

This study categorised the key participants with a score of 'not involved' and 'low involvement' as not integrated in the planning process and those with 'moderate involvement' and high involvement' as integrated in the planning process.

Table 2 shows that the overall degree of integration in the production of the project plans of refurbishment project is low, with the average score of involvement of 2.5. Out of six key participants, only three key participants, that is, Planning Engineer, Contract Manager and Site Manager are integrated in the decision making for the production of all of the four types of project plan. The Subcontractor is only integrated in two types of plan, that is Short-Term Plans and Method Statement. The Clients and Estimators are not integrated in the production of all project plans.

Table 2: The relative degree of involvement of the key participants in the production of four project plans

\begin{tabular}{lccccccc}
\hline Types of plan & $\begin{array}{c}\text { Planning } \\
\text { Engineer }\end{array}$ & $\begin{array}{c}\text { Contract } \\
\text { Manager }\end{array}$ & Site Manager & Subcontractor & Client & $\begin{array}{c}\text { Estimator } \\
\begin{array}{c}\text { Average } \\
\text { involvement }\end{array}\end{array}$ \\
\hline I Master Programme & 3.8 & 2.9 & 2.6 & 2.0 & 1.6 & 1.8 & 2.4 \\
2 Short-Term Plans & 3.0 & 3.2 & 3.6 & 2.9 & 1.6 & 1.8 & 2.6 \\
3 Method Statement & 3.1 & 3.3 & 3.2 & 2.9 & 1.5 & 1.5 & 2.6 \\
4 Site Layout & 2.9 & 3.3 & 3.5 & 1.8 & 2.0 & 1.3 & 2.4 \\
Average & 3.2 & 3.2 & 3.2 & 2.4 & 1.7 & 1.6 & 2.5 \\
\hline
\end{tabular}

\section{integrated Not integrated}

Score: < I.8(not involved), I.9-2.5 (Low Involvement), 2.6-3.2(moderate involvement), >3.3 (high involvement).

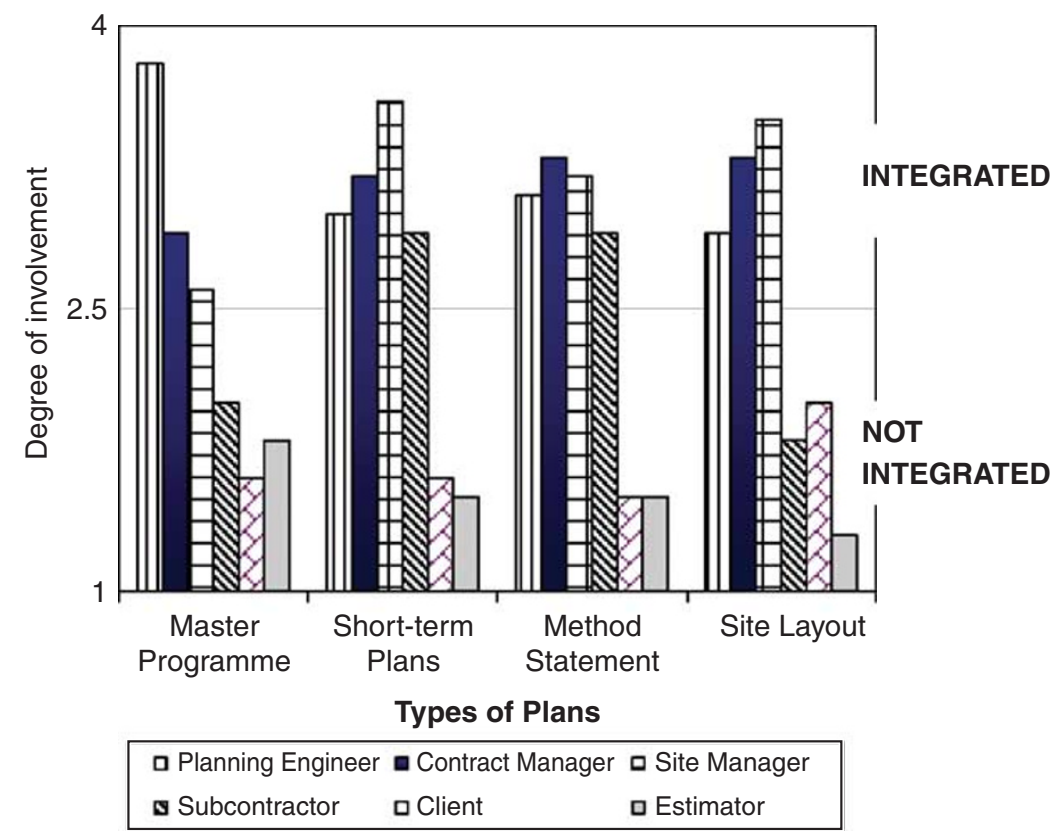

Figure I: The relative degree of involvement of the key participants in the production of four types of project plans. 
Figure 1 shows only in two types of project plans, that is, Short-Term Plans and Method Statements with more than half of the key participants are integrated in the production process.

\section{The involvement of the key participants in the production of Master Programme}

The Master Programme shows the relationship between an activity and the preceding and succeeding activities for the whole project. From the Master Programme, the resources required can be calculated. Without a programme of work, the execution of the contract will be haphazard and disordered. It needs to be produced holistically. Hence, this study hypothesised that the involvement of all the key participants in the production of Master Programme would be high.

However, it is surprising to find that the involvement of the key participants for the production of Master Programme, as a whole, is low. Figure 1 shows that only three key participants, that is, Planning Engineer, Contract Manager and Site Manager are integrated in the process. In fact, the Planning Engineer dominated the process.

The involvement of the Client in the production of Master Programme was expected to be high because most of the refurbishment projects were carried out in occupied buildings. The refurbishment works would affect the daily routine of the occupants or Clients within the building. Therefore, the occupants or the Clients would be concerned with how the activities in the refurbishment projects were sequenced. However, most of the Clients were not involved in the production of Master Programme.

Hence, it could be concluded that the production of Master Programme is a specialised task, with the involvement of only a few key participants and dominated by the Planning Engineer.

\section{The involvement of the key participants in the preparation of Short-Term Plans}

The Short-Term Plans encompass all programming and planning procedures undertaken during the construction stage, when the construction work progressed on site. These normally include the preparation of stage programmes every 4-6 weeks. The stage programmes enable the Master Programme to be broken down into greater detail and more manageable proportions and takes into account the latest resources and information available from the design team.

Figure 1 shows that four key participants, that is, Planning Engineer, Contract Manager, Site Manager and Subcontractors are integrated in the production of Short-Term Plans. Unlike the production of Master Programme, the production of Short-Term Plans is dominated by Site Manager. However, the involvement of the Planning Engineer in the production of Short-Term Plans is still high. This reflects the strong emphasis being placed on the integration of long-term planning and short-term planning in refurbishment projects.

Thus the production of Short-Term Plans is more integrated than the production of Master Programme. However, the overall involvement is only moderate, with a score of only 2.6.

\section{The involvement of the key participants in the production of Method Statement}

The Method Statement is also used by the project team to explore alternatives during the pre-construction stage. The Estimator should allow time and money in the plan for 
extensive consultation with users, neighbours and planning authorities. Therefore, the construction methods allowed for in the estimate must be flexible enough to enable reconsideration at the pre-contract planning stage as more detailed information becomes available. It is also used as a guide for the Site Manager for planning, for example, as the basis for requisitioning plant and forecasting the labour force needed. Therefore the involvement of Estimator during pre-construction stage is still vital.

The degree of integration in the production of Method Statement is similar to the production of Short-Term Plans. Figure 1 shows that four key participants are integrated in the production process. However, the Contract Managers dominated the production, with strong supports from the Planning Engineer, Site Manager and Subcontractor. Again, the Estimator and Client are excluded from the process.

\section{The involvement of the key participants in the production of Site Layout}

The Site Layout plans are mainly concerned with the efficiency of movement on the construction project site. Among the major decisions taken in the preparation of Site Layout is the provision of adequate access roads, location of major plant and areas for storage of materials.

Figure 1 shows that only three key participants, that is, Planning Engineer, Contract Manager and Site Manager are integrated in the production Site Layout. The Site Managers dominate the production. It is the least integrated among the four types of plan.

\section{Planning performance}

The planning performance of refurbishment projects are measured in terms of cost variance and time variance. Cost variance is the ratio of actual construction to target construction cost. When the value of cost variance is more than (1), it means that the actual cost is more than the target cost. Similarly, time variance is the ratio of actual construction time to target construction time. When the value of time variance is more then (1), it means the actual construction time is more than the target time.

Table 3 shows that slightly more than half of the refurbishment projects exceeded the target cost. In nearly a third of the refurbishments, the actual cost exceeded the target cost by more than 5 per cent.

Table 4 shows that more than half of the refurbishment projects exceeded the target time. Like the cost variance, nearly a third of the refurbishment projects exceeded the target time by more than 5 per cent. This result also supports the argument that refurbishment projects are uncertain, and difficult to control.

Therefore, it can be concluded that the planning performance of refurbishment projects is generally unsatisfactory, with more than half of them exceeding the target cost and target time. The pertinent question is to what extent the involvement of the key participants in the production of plans could improve the planning performance.

Table 3: The cost variance of refurbishment projects

\begin{tabular}{lc}
\hline Cost variance & Refurbishment projects $(N=67), \%$ \\
\hline Less than 0.90 & 25.5 \\
$0.91-0.95$ & 7.3 \\
$0.96-1.00$ & 16.4 \\
I.0I-I.05 & 20.0 \\
I.06-I.I0 & 20.0 \\
More than I.10 & 10.9 \\
Total & 100.0 \\
\hline
\end{tabular}


Table 4: The time variance of refurbishment projects

\begin{tabular}{lc}
\hline Time variance & Refurbishment projects $(N=67), \%$ \\
\hline Less than 0.90 & 9.4 \\
$0.91-0.95$ & 6.2 \\
$0.96-1.00$ & 31.2 \\
I.0I-I.05 & 21.9 \\
I.06-I.10 & 17.2 \\
More than 1.10 & 14.1 \\
Total & 100.0 \\
\hline
\end{tabular}

\section{Associations between the degree of involvement in the production of plans and planning performance}

It would be interesting to investigate the association between the involvement of the key participants in the production of the four types on plan and planning performance.

This study uses Spearman's correlation technique to establish the associations between the involvement of the key participants and planning performance. The independent variables are the involvement of the key participants that include Estimator, Planning Engineer, Contract Manager, Site Manager, Subcontractors and Clients. The dependent variables are the planning performance, that is, cost variance and time.

Thus the research (alternative) hypothesis to be tested in this article is:

- The level of involvement of the key participants in the production of plans affects the planning performance.

- The Null hypothesis is rejected at 0.05 significant level. Negative correlations were expected between the independent and dependent variables.

The results are shown in Tables 5-8.

The results from Tables 5-8 show only one significant correlation, that is the association between the involvement of Client in the production of Master Programme and time variance. Thus in general, the Null hypothesis cannot be rejected. It means that little evidence to support the research hypothesis that the involvement in the production of project plans has significant impact on planning performance.

\section{DISCUSSION}

The results above show that:

1. The overall degree of integration is low in the preparation of the four types of project plan.

2. The production of two project plans, that is, the Master Programme and the Method Statement are integrated, whereas the production of Short-Terms and Site Layout are not.

3. Only three key participants are integrated in the production of all project plans.

4. The productions of different project plans are dominated by different key participants. The production of Master Programme is dominated by Planning Engineers, Method Statement dominated by Contract Manager and Short-Term Plans and Site Layout dominated by Site Managers.

5. Overall, Subcontractors, Estimators and Clients are not integrated in the process.

6. Generally, a higher degree of involvements of the key participants in the production of the plans do not significantly improve the planning performance. 
Table 5: The associations between the involvements of the key participants in the production of Master Programme and planning performance

\begin{tabular}{lcc}
\hline Key participants & Cost variance & Time variance \\
\hline Estimator & -0.043 & 0.004 \\
Planning Engineer & 0.097 & -0.036 \\
Contract Manager & -0.094 & -0.135 \\
Site Manager & 0.143 & 0.073 \\
Subcontractor & -0.034 & -0.043 \\
Client & -0.194 & $-0.339 * *$ \\
\hline
\end{tabular}

**Correlation is significant at the 0.01 level (2-tailed).

Table 6: The associations between the involvement of the key participants in the production of Short-Term Plans and planning performance

\begin{tabular}{lcc}
\hline Key participants & Cost variance & Time variance \\
\hline Estimator & 0.027 & 0.125 \\
Planning Engineer & 0.115 & 0.122 \\
Contract Manager & 0.159 & 0.090 \\
Site Manager & 0.125 & -0.059 \\
Subcontractor & 0.203 & 0.222 \\
Client & -0.049 & -0.149 \\
\hline
\end{tabular}

Table 7: The associations between the involvements of the key participants in the production of method statement and planning performance

\begin{tabular}{lcr}
\hline Key participants & Cost variance & Time variance \\
\hline Estimator & -0.107 & 0.080 \\
Planning Engineer & 0.126 & 0.050 \\
Contract Manager & -0.078 & 0.066 \\
Site Manager & 0.145 & 0.100 \\
Subcontractor & 0.111 & 0.211 \\
Client & 0.097 & -0.042 \\
\hline
\end{tabular}

Table 8: The associations between the involvements of key participants in the production Site Layout and planning performance

\begin{tabular}{lcc}
\hline Key participants & Cost variance & Time variance \\
\hline Estimator & -0.169 & 0.147 \\
Planning Engineer & 0.150 & 0.031 \\
Contract Manager & -0.073 & 0.042 \\
Site Manager & 0.098 & 0.121 \\
Subcontractor & 0.239 & 0.283 \\
Client & -0.052 & -0.177 \\
\hline
\end{tabular}

The results show that refurbishment project organisations treat the production of project plans as a specialised task. Planning is done by a selected few, that is, Planning Engineer, Contract Manager and Site Manager. Thus, the argument that the uncertainty of refurbishment projects requires greater integration has not been well supported. It seems that the approach to planning process for refurbishment projects is not significantly different that for new build, where specialisation prevails. One plausible explanation is that organisation, contractual arrangement, education and training in the construction 
industry are more centred to new construction. These must have influenced the management approach of refurbishment projects.

Furthermore, involvements in the production of the project plans require resources, both in terms of efforts and time. Laufer et al (1994) highlighted that planning takes a lot of time for documentation and the preparations of plans (in the forms of tables, charts and diagrams), as well their dissemination and communication. The presentation of decisions into plans requires special training, technical skill and experience in the use of computer and planning software. It would be inefficient to involve all the key participants in the planning process, especially when their knowledge in it is limited. It could be argued that not many Clients are willing to be involved in planning owing to their lack of time. However, it must be noted that most of the buildings undergoing refurbishment included in this survey were occupied. Therefore, the refurbishment works would impinge of the Clients daily activities within the buildings and vice-versa. Hence, the involvement of the Client would be vital.

It would not be easy to involve the Estimators who have to produce estimates for bidding of many projects. In most construction firms, the Estimator is mainly responsible for the build-up of the unit rates for inclusion in the priced bill. This also involves obtaining materials and Subcontractors quotations. Often the Estimator has to bid for many projects simultaneously. As Stukhart et al (1986) pointed out that contractors have little control over the pace and timings at which bids are issued, and less still over awards of contracts. In the case of refurbishment projects, it is very difficult to pull out an Estimator from an active project and to assign him immediately to a new one. He must turn his attention immediately to putting a new estimate for another project. However, it could be argued that there are benefits of integrating Estimator in the preparation of plans. In an uncertain construction project in which changes are endemic, the success of the projects is determined by the degree of integration of the key participants with different skills involved in the planning process. The Estimator who holds vital cost-information and labour constants and productivities would contribute significantly to monitoring cost and time variance.

The low involvement of Subcontractors in the production of the project plans is not totally surprising. Most Subcontractors would only be willing to be involved if the production of the project plans if it concerns to their work. Therefore, their involvement is in ad hoc manner. They only get involved as and when required.

Another reason for low integration in the planning process can be attributed to McGowan et al's (1993) argument that specialisation is linked to clear definition of responsibility and lesser tendency for conflicts to occur within the construction project organisations. Thus planning tasks are given to specialists.

However, it is important to note that the involvement of Site Managers in the preparation of Master Programme is high. Thus, the argument that Planning Engineers tending to concentrate on long-term planning and the Site Managers tend to concentrate on short-term project planning could be rejected.

However, the result of this study has shown the importance of the Client to be integrated in the production of Master Programme. Higher involvement of Clients in the production of Master Programme would significantly improve the time variance. Considering that most of the refurbished buildings surveyed in this article were occupied, the schedules in the Master Programme must take into account the disturbances that originate from the routine activities of the Clients. The Clients also need to be informed on how the refurbishment works could impinge on their daily activities. Clients' involvement would create better understanding between the parties and could avoid major disruptions in the refurbishment projects. 


\section{CONCLUSIONS}

This study investigates relative involvement of the key participants, which include the Estimator, Planning Engineer, Contract Mangers, Site Managers, Subcontractors and Client, in the production of four major plans, that is, Master Programme, Short-Term Plans, Method Statement and Site Layout. It was found that specialisation is the norm in the planning process of refurbishment projects. The tasks of producing the project plans are dominated by Planning Engineer, Contract Manager and Site Manager. The involvements of the other key participants are low.

The planning performance of refurbishment projects is also low. More than half of the refurbishment projects exceeded the budget and targeted time. The correlation test indicates that the involvement of Client could significantly improve the time variance.

\section{REFERENCES}

Argyris, C. (1972) The Applicability Of Organizational Theory. Cambridge: Cambridge University Press.

Bass, B.M. and Leavitt, H.J. (1963) Some experiments in planning and operating. Management Science 9: 74-85.

Boyd, D. and Weaver, P. (1994) Improving the management and operations of refurbishment projects. Proceedings of the 10th. ARCOM Annual Conference; 14-16 September 1994. Loughbrough, UK: Loughbrough University of Technology.

Bresnen, M. (1990) Organising Construction: Project Organisation and Matrix Management. London: Routledge. Buffa, E.S. (1976) Operations Management. Santa Barbara, CA: Wiley.

Burns, T. and Stalker, G. (1961) The Management of Innnovation. London: Tavistock.

Chartered Institute of Building CIOB. (1988) Project Management in Building, 2nd edn. Ascot, UK: CIOB.

Cohenca, D., Laufer, A. and Ledbetter, W.B. (1987) Factors affecting construction planning efforts. Journal of Construction Engineering and Management 115(1): 70-89.

Cohenca-Zall, D., Laufer, A., Shapira, A. and Howell, A.G. (1994) Process of planning during construction. Journal of Construction Engineering and Management 120(3): 561-579.

Cooke, B. (1993) Contract Planning and Contractual Procedures, 3rd edn, Hamphshire, UK: MacMillan.

Cormican, D. (1985) Construction Management: Planning and Finance. London: Construction Press.

Cyert, R. and March, J.G. (1963) A Behavioural Theory of the Firm. Englewood Cliffs, NJ: Prentice-Hall.

Dermer, J. (1977) Management Planning and Control Systems. Georgetown, Ontario: Irwin-Dorsey.

Dickson, J. (1981) The relation of direct and indirect participation. Industrial Relations Journal 12(4): 27-35.

Egbu, C.O. (1994) Management education and training for construction work within the construction industry. $\mathrm{PhD}$ thesis, University of Salford, England.

Faniran, O.O., Oluwoye, J.O. and Lenard, D. (1994) Effective construction planning. Journal of Construction Management and Economics 12: 485-499.

Fiedler, K. (1987) Special conditions for time scheduling of building modernisation process. International Journal of Project Management 9(1): 53-60.

Filley, A.C., House, R.J. and Kerr, S. (1976) Managerial Process and Organizational Behaviour. Glenview, IL: Foresman.

Galbraith, J.R. (1977) Organization Design. Reading, MA: Addison-Wesley.

Harrison, F.L. (1992) Advanced Project Management: A Structured Approach, 3rd edn. Aldershot, UK: Gower.

Heller, F., Drenth, P., Koopman, P. and Rus, V. (1989) Decisions in Organizations: A Three-Country Study. London: SAGE Publications.

Hillebrandt, P.M. (1974) Economics Theory and the Construction Industry. London: Macmillan.

Jenkins Jr, G.D. and Lawler, E.E. (1981) Impact of employee participation in pay plan development. Organizational Behaviour and Human Performance 28: 111-128.

Kavic, B., Rus, V. and Tannebaum, A.S. (1971) Control, participation and effectiveness. Administrative Science Quarterly 16: 74-86.

Koontz, H. and O'Donnel, C. (1972) Principles of Management: An Analysis of Managerial Functions, 5th edn. Tokyo, Japan: McGraw-Hill.

Laufer, A. and Cohenca, D. (1988) Factors Affecting Planning Efforts and Outcomes. Building Research Station, Technion, IIT, Haifa, Israel. Technical Report. 
Laufer, A., Denker, G. and Shenhar, A. (1996) Simultaneous management: The key to excellence in capital projects. International Journal of Project Management 14: 102-108.

Laufer, A., Shapira, A. and Cohenca-Zall, D. (1992) The Process of Construction Planning and its Product: Practice in Mature Companies. National Building Research Institute, Technion-IIT, Haifa, Israel. Research Report.

Laufer, A., Shapira, A. and Cohenca-Zall, D. (1993) Prebid and preconstruction planning process. Journal of Construction Engineering and Management 119(3): 426-443.

Laufer, A. and Tucker, R.L. (1988) Competence and timing dilemma in construction planning. Construction Management and Economics 6: 339-355.

Laufer, A., Tucker, R.L., Shapira, A. and Shenhar, A.J. (1994) The multiplicity concept in construction project planning. Construction Management and Economics 11: 53-65.

Lawrence, P.R. and Lorsch, J.W. (1967) Organization and Environment. Boston, MA: Harvard Business School.

Likert, R. (1967) The Human Organization: Its Management and Value. London: McGraw-Hill.

Marsh, P. (1983) The Refurbishment of Commercial and Industrial Buildings. London: Construction Press.

Marsh, J.G. and Simon, H.A. (1958) Organisations. New York: Wiley.

McGowan, P.H., Randall, C.W. and Horner, R.M.W. (1993) Resource significant models for estimating, planning and control in construction. CIB W78 Workshop, 13 August, National University of Singapore.

Miles, R.E. (1965) Human relations or human resources. Harvard Business Review (July-August): 148-163.

O’Brien, J.J. (1984) CPM in Construction Management, 3rd edn. New York: McGraw-Hill.

Office for National Statistics. (2009) Statistical Bulletin: Output in the construction industry. 1st quarter 2009, Newport, UK.

Okoroh, M.C. (1992) Knowledge-based decision support system for the selection and appointment of subcontractors for building refurbishment contracts. PhD thesis, Loughborough University, UK.

Pennings, J.M. (1976) Dimensions of organisational influence and their effectiveness correlates. Administrative Science Quarterly 21: 88-99.

Quah, L.K. (1992) Comparative variability in tender bids for refurbishment and new build work. Construction Management and Economic Journal 10: 263-269.

Rahmat, I.B. (1997) Planning and control process of refurbishment projects. PhD thesis, University College London.

Simon, H.A. (1960) The New Science of Management Decisions. New York: Harper \& Row.

Syal, M.G., Grobler, F., Willenbrock, J.H. and Parfitt, M.K. (1992) Construction project process planning model for small-medium builders. Journal of Construction Engineering and Management 118(4): 653-663.

Stukhart, G., Heme, W.L. and Neil, J.M. (1986) Construction Contractor Planning for Fixed Price Construction, A report to the Construction Industry Institutes, Texas A\&M University, Texas, USA.

Tannebaum, A. (1968) Control in Organization. McGraw-Hill: New York.

Walker, A. (1989) Project Management in Construction, 2nd edn. London: BSP Professional books.

Whiteman, W.E. and Irwig, H.G. (1988) A disturbance scheduling technique for managing refurbishment work. Journal of Construction Engineering Management 114: 191-213.

Young, B., Torrance, V.B. and Egbu, C.O. (1996) Managing refurbishment works in the construction and shipping industries. Faculty of the Built Environment, University College London, UK. 